\title{
Enhanced Effectiveness of Liquid Thermal Fire Extinguishing Agents
}

\author{
JIANN C. YANG ${ }^{1}$, WILLIAM M. PITTS ${ }^{1}$, and MARCIA L. HUBER ${ }^{2}$ \\ ${ }^{1}$ Building and Fire Research Laboratory \\ National Institute of Standards and Technology (NIST) \\ 100 Bureau Drive, Gaithersburg, Maryland 20899, U.S.A. \\ and \\ ${ }^{2}$ Chemical Science and Technology Laboratory \\ National Institute of Standards and Technology \\ 325 Broadway, Boulder, Colorado 80305, U.S.A
}

\begin{abstract}
This paper describes the findings of a study designed to identify and characterize super-effective thermal fire-fighting agents as possible halon replacements. Two existing thermodynamic databases have been searched in order to identify chemical compounds, which are predicted to extract large amounts of heat from a combustion zone. Additional substances that are not well represented in these databases were included. Compounds having high (1) heats of vaporization, (2) liquid-phase heat capacities, and (3) total heat absorption due to phase changes (if applicable), heating of a liquid (if applicable), and heating of the gas phase to combustion temperatures were identified.
\end{abstract}

Two compounds, methoxy-nonaflurobutane (HFE7100) and lactic acid, were identified as being especially interesting. Both agents and water were tested in the Dispersed Liquid Agent Fire Suppression Screen (DLAFSS) apparatus. Lactic acid was tested in mixtures with water at various concentrations. The $\mathrm{acid} /$ water mixtures were found to be less effective than water alone, indicating that the lactic acid was reacting and releasing heat that more than compensated for the heat extraction.

HFE7100 and water were also tested in a screening apparatus known as the Transient Application Recirculating Pool Fire (TARPF) that incorporates a flame stabilized behind a bluff body in a turbulent oxidizer flow. The agent failed to extinguish a propane flame when it was released at nominal mass fraction in air twice as high as the extinguishing mass fraction measured in the DLAFSS. This observation is attributed to ineffective mixing and entrainment of liquid droplets into the flame.

A simple thermodynamic analysis under-predicts the performance of the liquid thermal agents in the DLAFSS. Additional studies of the effectiveness of fire extinguishing agents released as liquids should be performed with a focus on confirming and understanding their enhanced performance relative to that expected based on simple heat extraction.

KEYWORDS: fire suppression, halon replacement, liquid droplets.

\section{INTRODUCTION}

The use of halon $1301\left(\mathrm{CF}_{3} \mathrm{Br}, \mathrm{R} 13 \mathrm{~B} 1\right)$ for fire fighting is being phased out due to its deleterious effects on stratospheric ozone. Because of the concern over the impacts of this phase-out on the operational safety and mission capabilities of system platforms, a research and technology development program, termed the Next Generation Fire Suppression Technology Program (NGP), was formulated and implemented by the U.S. Department of Defense. This paper, as a part of the NGP, summarizes the findings of a detailed study to characterize and identify highly effective liquid thermal fire-fighting agents as possible replacements for halon 1301 [1]. In this paper, "thermal" agents refer to chemical compounds that act simply by extracting heat from a flame zone and lowering the temperature to a point where combustion can no longer be sustained. These types of agents should be contrasted with "chemical" agents that generate active chemical species (e.g., the bromine atoms generated by halons) that interfere with the radical chain branching mechanisms required to sustain combustion.

There are a number of endothermic physical processes that can extract heat from a gaseous flame zone, thus lowering the temperature and ultimately leading to flame extinguishment. These include simple heating (i.e., heat capacity) of an agent, phase changes such as vaporization of a liquid or sublimation of a 
solid, endothermic molecular decomposition (note that this process is classified as a physical process as long as the initial agent and its products do not participate in the combustion chemistry), and simple dilution which can modify flame temperatures by spreading the heat released by combustion over larger volumes and by slowing three-body reactions due to lower species collision rates. Several aspects related to the effectiveness of potential thermal agents have been examined [1]. The study reported herein focuses on identifying and evaluating liquid chemicals likely to be particularly effective as thermal fire extinguishing agents.

Two thermophysical property databases were used to search for compounds predicted to absorb large amounts of heat. The first was the DIPPR (Design Institute for Physical Properties) Database [2] which contained 1458 substances from 83 family types. The second was REFPROP [3] which was a smaller database and contained 43 alternative refrigerants including many candidates for replacing hydrochlorofluorocarbons (HCFCs). Note that this search was by no means exhaustive and might exclude some of the developmental chemical compounds due to the limited content of the two databases and the lack of accessibility and availability to other chemical compound databases.

In addition, representative substances from other chemical families not well represented in the existing thermophysical property databases, such as fluorinated ethers, alcohols and amines, were included. The fluorinated ethers are especially interesting since their atmospheric lifetimes may be significantly lower than those of chlorofluorocarbons [4]. Some of these have been identified as possible replacements for blowing agents, refrigerants, fire suppression agents, and as solvents [5],[6],[7],[8],[9],[10]. Several cyclic fluorinated ether compounds, some non-cyclic methyl ethers, fluorinated methyl ethyl ethers with two or fewer hydrogen atoms, and some larger fluorinated ethers were also selected in the search. In addition to the fluorinated ethers, two fluorinated amines, the refrigerant HFC-338mccq $\left(\mathrm{CH}_{2} \mathrm{FCF}_{2} \mathrm{CF}_{2} \mathrm{CF}_{3}\right)$, and the fluorinated alcohol 2,2,3,3,3-pentafluoropropanol $\left(\mathrm{CF}_{3} \mathrm{CF}_{2} \mathrm{CH}_{2} \mathrm{OH}\right)$ were added to the list.

The desirable physical properties for thermal agents are high latent heats of vaporization and high liquid and vapor heat capacities. In order to characterize the potential effectiveness of a thermal agent, the total heat absorbed by the fluid from room temperature up to $1400 \mathrm{~K}$, which was selected as a representative flame temperature, was calculated. The actual flame temperature used is unlikely to affect the relative ordering of agents. The total heat absorbed consists of three contributions,

$$
\Delta H^{\text {Total }}=\int_{298 K}^{T_{b}} C_{p}^{\text {liquid }} \mathrm{d} T+\Delta H_{v}+\int_{T_{b}}^{1400 K} C_{p}^{\text {gas }} \mathrm{d} T,
$$

where the first term in the right hand side is the enthalpy change $\left(\Delta H_{l}\right)$ from heating the liquid from room temperature up to the normal boiling point, $T_{b}$. Since the heat capacity of a liquid, $C_{p}^{\text {liquid }}$, does not change significantly over a small temperature range, liquid heat capacity at the normal boiling point was used in the calculations. The second term is the latent heat of vaporization at the normal boiling point, $\Delta H_{v}$. The third term is the enthalpy change $\left(\Delta H_{g}\right)$ from heating the vapor from the normal boiling point to $1400 \mathrm{~K}$. For agents with boiling points below $298 \mathrm{~K}$, the total heat involved is just the contribution $\Delta H_{v}$.

Based on the results of the search [1], two chemicals (methoxy-nonafluorobutane and lactic acid) and water were identified as being particularly interesting for their predicted ability to extract heat. Table 1 summarizes various parameters for the two compounds and water.

Lactic acid, $\mathrm{CH} 3 \mathrm{CH}(\mathrm{OH}) \mathrm{COOH}$, is a strong irritant to the skin, corrosive in concentrated form, and flammable. Clearly, this compound alone is not a potential candidate as a fire suppression agent. However, based solely on its ability to extract heat, it is estimated to be nearly twice as effective on a mass basis as any of the other potential thermal agents considered, except water. Its ability to extract heat is predicted to be roughly $2 / 3$ of that of water on a mass basis and 3.5 times greater on a molar basis. Since lactic acid is soluble in water, it was deemed worthwhile to investigate the suppression characteristics of mixtures of these two polar liquids delivered to the flame as droplets.

Methoxy-nonafluorobutane (HFE7100, C4F9OCH3) is available commercially [11]. It was developed as a replacement for ozone-depleting chemicals used in a variety of applications and has been estimated to have a zero ozone-depletion potential, a relatively low global-warming potential, favorable toxicological properties, and good materials compatibility properties [11]. It has been approved under the Significant New Alternatives Policy (SNAP) of the United States Environmental Protection Agency. There is an 
existing patent dealing with use of HFE7100 as a fire-extinguishing agent [12]. Based on these favorable properties, it was decided to experimentally characterize the extinguishing capability of HFE7100.

Table 1. Liquid heat capacity $C_{p}^{\text {liquid }}$ at normal boiling $T_{b}$, heat of vaporization $\Delta H_{v}$ at $T_{b}$, and the enthalpy change $\Delta H_{\text {total }}$ from heating the liquid from $298 \mathrm{~K}$ to $1400 \mathrm{~K}$.

\begin{tabular}{|l|c|c|c|c|c|}
\hline \multicolumn{1}{|c|}{ Compound } & $\begin{array}{c}\boldsymbol{T}_{\boldsymbol{b}} \\
(\mathrm{K})\end{array}$ & $\begin{array}{c}\boldsymbol{C}_{\boldsymbol{p}}^{\text {liquid }} \\
(\mathrm{J} / \mathrm{mol} \mathrm{K})\end{array}$ & $\begin{array}{c}\boldsymbol{\Delta} \boldsymbol{H}_{\boldsymbol{v}} \\
(\mathrm{kJ} / \mathrm{mol})\end{array}$ & $\begin{array}{c}\Delta \boldsymbol{H}_{\text {total }} \\
(\mathrm{kJ} / \mathrm{mol})\end{array}$ & $\begin{array}{c}\Delta \boldsymbol{H}_{\text {total }} \\
(\mathrm{kJ} / \mathrm{kg})\end{array}$ \\
\hline water & 373.1 & 76.0 & 40.0 & 87.5 & 4856 \\
\hline $\begin{array}{l}\text { lactic acid, } \\
\text { C3H6O3 }\end{array}$ & 455 & 290.1 & 59.2 & 292.9 & 3252 \\
\hline $\begin{array}{l}\text { methoxy- } \\
\text { nonafluorobutane, } \\
\text { HFE7100 }\end{array}$ & 334 & 292.8 & 30.3 & 407.6 & 1630 \\
\hline
\end{tabular}

It is of interest to compare the relative contributions of the various heat extraction mechanisms included in Eq. 1. Figure 1 shows a bar plot of the three heat extraction processes for the two liquid agents identified for further investigation, and water in terms of heat extraction per mole of agent. The four gaseous thermal agents (nitrogen, argon, helium, and carbon dioxide) are included for comparison. On a molar basis HFE 7100 is predicted to be the most effective, with lactic acid a close second. The contribution of liquid processes to the total heat extraction is relatively small for HFE7100. Liquid water is predicted to be the next most effective due primarily to the relatively high heat absorbed during evaporation. The four gaseous agents are predicted to be relatively ineffective and are ordered $\mathrm{CO}_{2}>\mathrm{N}_{2}>\mathrm{Ar}=\mathrm{He}$.

\section{Estimated Total Heat Extraction ( $\mathrm{kJ} / \mathrm{mol})$}

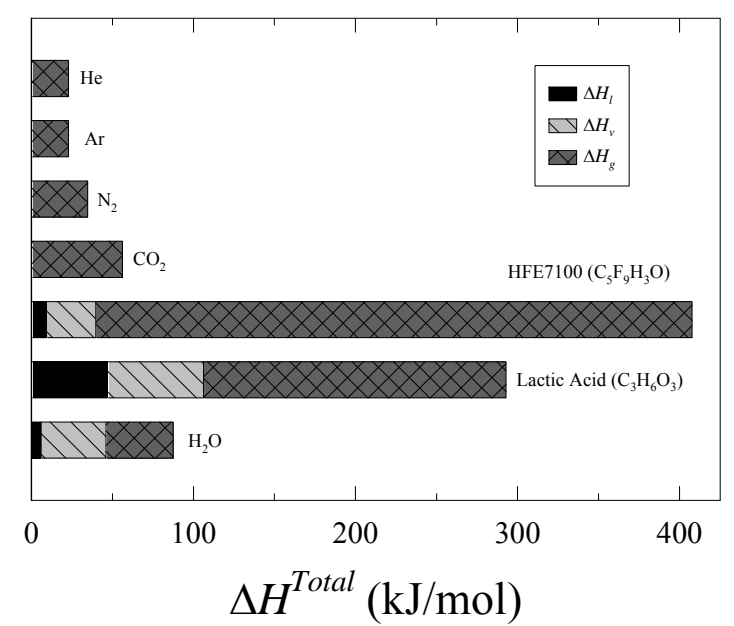

Fig. 1. The relative contributions of liquid heating, vaporization, and gas heating to $1400 \mathrm{~K}$ to the total heat absorbed by various thermal agents on a per mole basis are shown as bar graphs.

The results included in Fig. 1 have been replotted in Fig. 2 on a per mass basis. The plot now has a very different appearance. The most effective agent in these terms is helium, followed by water and lactic acid. On this plot the role of heat extraction by heating and vaporization of the liquid agents is clear. It can be seen that for water over half of the heat extraction arises from the liquid processes. For lactic acid the contribution of liquid vaporization to the total heat extraction is significant, but greatly reduced as compared to water. The large differences between the HFE7100 and lactic acid and water are due to hydrogen bonding that exists in water and lactic acid. This bonding significantly increases the amount of heat energy required to vaporize liquids when it is present. 
Note that nitrogen and carbon dioxide are predicted to extract roughly the same amount of heat per kilogram, while the amount extracted by gaseous HFE7100 is only slightly higher. In fact, it has been found that for a number of gaseous species expected to act primarily as thermal agents the mass required to extinguish a fire is roughly constant [13]. However, it is clear from the results shown that this criterion should only be used to provide guidance and that it is not generally applicable to a wide range of chemical species.

\section{Estimated Total Heat Extraction $(\mathrm{kJ} / \mathrm{kg})$}

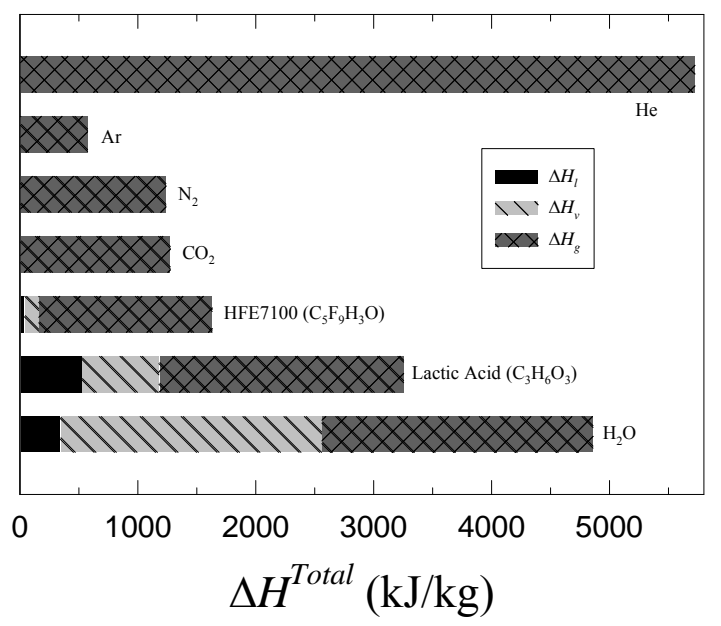

Fig. 2. The relative contributions of liquid heating, vaporization, and gas heating to $1400 \mathrm{~K}$ to the total heat absorbed by various thermal agents on a per mass basis are shown as bar graphs.

\section{APPARATUS}

The fire suppression effectiveness of water, lactic acid/water mixtures, and HFE 7100 were characterized using the two screening apparatus developed recently at NIST. The first screening apparatus is the Dispersed Liquid Agent Fire Suppression Screen (DLAFSS) Apparatus. A detailed description of the apparatus is available elsewhere [14]. Figure 3 shows a schematic for the DLAFSS.

The apparatus consists of a small vertical wind tunnel, a water-cooled porous cylindrical burner located at the test section, and a small nebulizer located in the settling chamber of the tunnel. This type of burner configuration is often referred to as a "Tsuji burner [15]". The fuel for the burner was propane with a volumetric flow rate of $2 \mathrm{~L} / \mathrm{min}$, corresponding to a nominal velocity of $4.2 \mathrm{~cm} / \mathrm{s}$. Air is supplied to the tunnel via a frequency-controlled blower. The nebulizer, located in the settling chamber, is used to generate a small poly-dispersed spray of liquid droplets. The droplet Sauter mean diameters (measured using a phase Doppler interferometer) at the burner location without the flame, varied between $25 \mu \mathrm{m}$ and $35 \mu \mathrm{m}$ under the test conditions.

The experiments were conducted by increasing the airflow through the tunnel with a fixed liquid delivery rate to the nebulizer. The droplets were entrained by the airflow and were transported to the test section. The air velocity at which the flame at the forward stagnation region of the burner was blown-off was used as an indicator for comparing fire suppression efficiencies of various liquid agents.

The second screening apparatus is the modified Transient Application Recirculating Pool Fire (TARPF) facility, which was originally developed to assess the effectiveness of gaseous agents for suppressing flames attached behind a bluff body in a turbulent airflow. The facility was designed to generate flow conditions typical of those present in aircraft engine nacelles. This facility was selected as a test bed because this flame configuration is believed to be particularly challenging for liquid agents.

The TARPF is a horizontal, open-circuit wind-tunnel with a flat porous burner located behind a baffle or a backward-facing step where a propane flame simulating a pool fire can be stabilized. A gaseous agent is transiently or impulsively introduced upstream into the air stream for a short duration. Suppression effectiveness is assessed based on the amount of agent required to extinguish the flame as a function of the 
application duration and the airflow within the tunnel. A detailed description of the TARPF facility has been provided by Grosshandler et al. [16], [17].

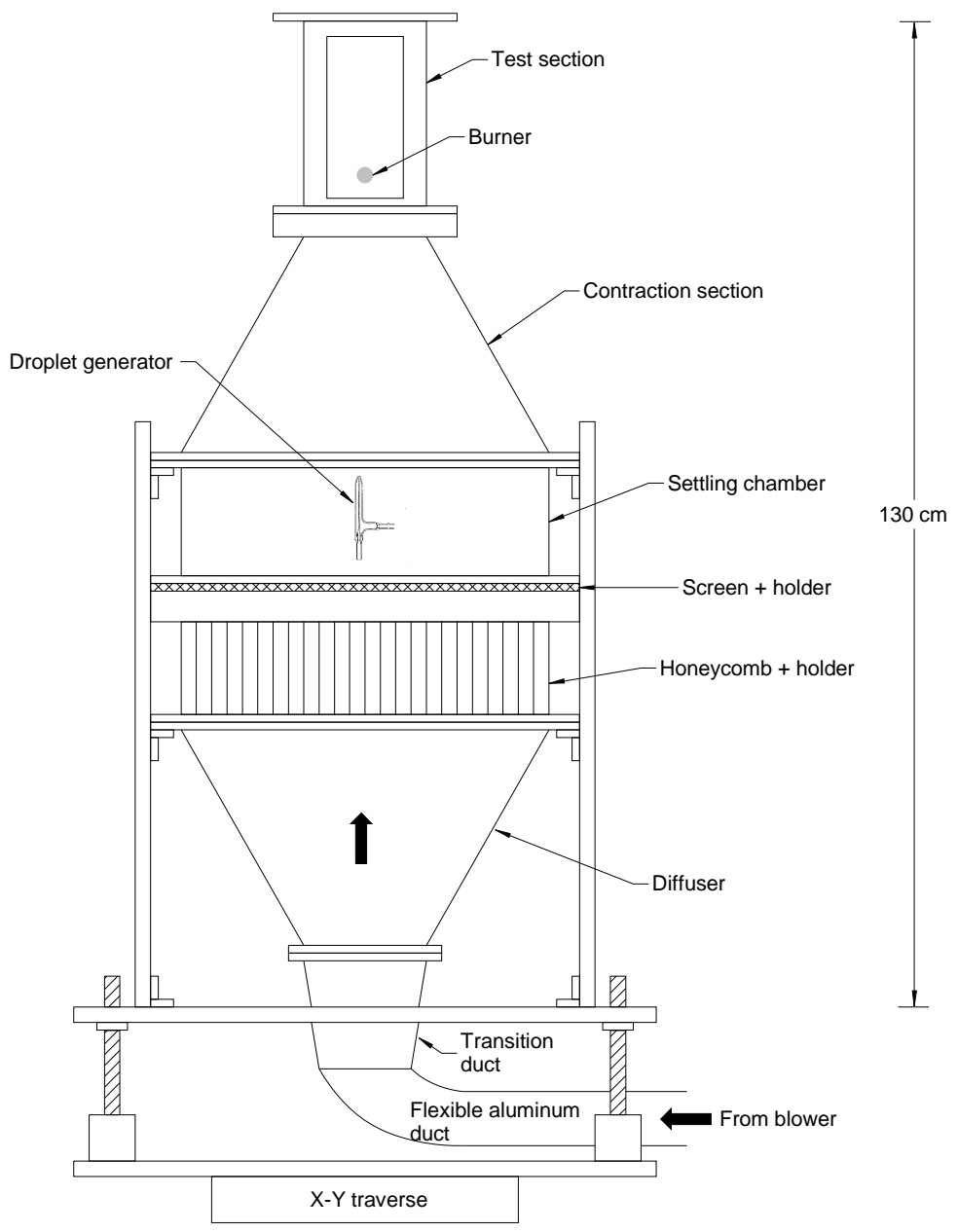

Fig. 3. Schematic of DLFASS.

The TARPF facility was modified to accommodate the application of a liquid agent as a mist. Figure 4 shows a schematic of the modified TARPF facility. The liquid dispensing system consisted of a liquid reservoir, a compressed air cylinder, two computer-controlled solenoids, and a mist-jet hollow-cone nozzle. The nozzle was positioned $65.5 \mathrm{~cm}$ upstream of the porous burner in the horizontal center and at a height corresponding to the midway point between the top of the ramp and the top of the wind tunnel. According to the manufacturer's specifications, the nozzle has a nominal spray angle of $70^{\circ}$ when operated at $1.03 \mathrm{MPa}$ with a flow rate of $1.9 \mathrm{~mL} / \mathrm{s}$. Information on droplet-size distributions was unavailable from the manufacturer. In situ droplet characterization using a phase Doppler interferometer proved to be difficult with the existing experimental configuration and limited optical access. In order to generate a mist for a fixed duration, the computer activated the solenoid connected to the reservoir. At the end of the discharge, this solenoid was deactivated to terminate the flow to the nozzle, and the second solenoid leading to drain was simultaneously activated to prevent any residual flow to and/or dripping from the nozzle.

\section{RESULTS AND DISCUSSION}

Despite its expected ability to withdraw significant levels of heat from a flame zone, lactic acid is flammable [2]. There are competitive effects between the heat release and heat extraction in the flame suppression processes. One approach for mitigating the effect of the heat release is to mix lactic acid with a good thermal agent like water, which is miscible with lactic acid. The mixing of lactic acid with water may also offer potential synergistic effects for fire suppression effectiveness. 


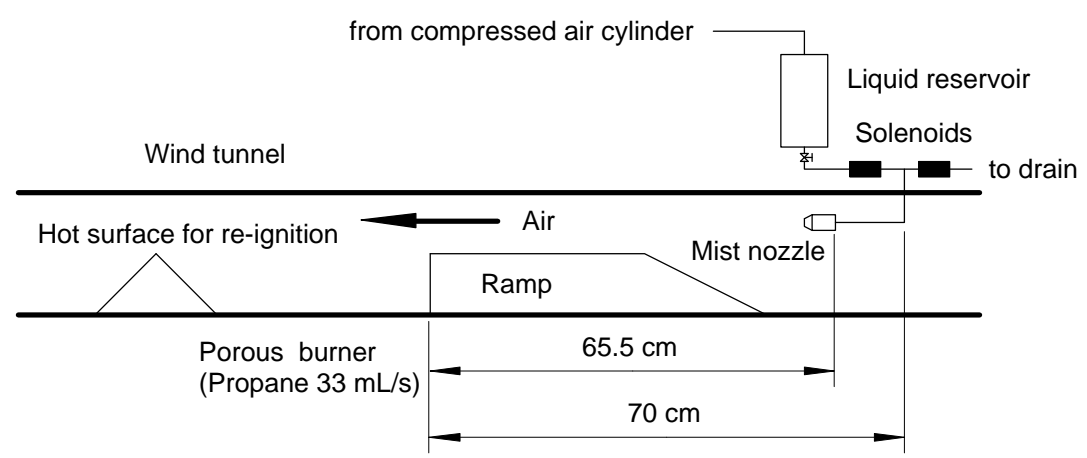

Fig. 4. Schematic of the modified TARPF facility.

In order to explore the effectiveness of a lactic acid/water mixture as a potential thermal agent, it is necessary to know the latent heat of vaporization for the mixture. The estimation of the latent heat of vaporization for this case is more complicated than for a pure fluid. In a mixture at constant pressure, as the liquid is heated it will begin to boil once it reaches the bubble point temperature of the mixture. At this point, the composition will begin to change (unless it is an azeotrope). As the vaporization continues at constant pressure, the more volatile substance (water in this case) will concentrate in the vapor phase, while the liquid phase will become more concentrated in lactic acid. The temperature will rise from the bubble point temperature to the dew point temperature. A T-x,y diagram ( $x$ and $y$ being the mole fractions of the liquid and vapor phase respectively) for lactic acid/water mixtures at a constant pressure of $0.101 \mathrm{MPa}$ was constructed using the Peng-Robinson equation of state with a binary interaction parameter of 0.88 [18] and did not reveal any indication of an azeotrope. Figure 5 shows the $T-x, y$ diagram.

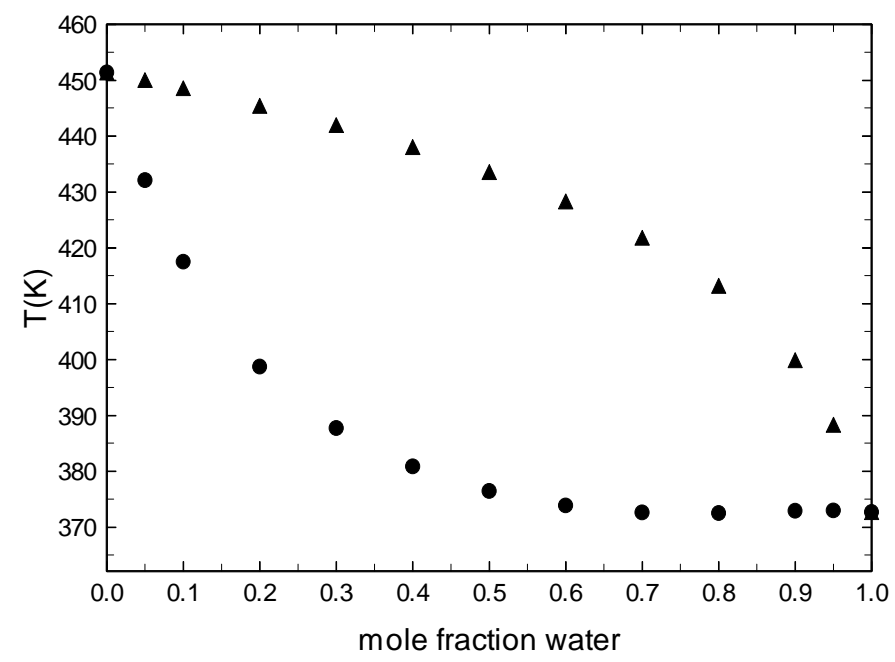

Fig. 5. T- $x, y$ diagram for lactic acid/water mixtures at $p=0.101 \mathrm{MPa}$.

Assuming that the entire sample is vaporized, then the integral heat of vaporization at constant pressure can be found by $\Delta H_{\text {vap }}=H_{d}-H_{b}$, where $H_{d}$ is the enthalpy of the saturated vapor at the dew point and $H_{b}$ is the enthalpy of the saturated liquid at the bubble point. Figure 6 shows the enthalpies of the saturated vapor at the dew point and the saturated liquid at the bubble point.

The latent heat of vaporization $(\mathrm{kJ} / \mathrm{mol})$ was calculated and fitted to a polynomial:

$\Delta H^{v a p}=62.35+51.71 x-130.1 x^{2}+57.92 x^{3}$

where $x$ is the mole fraction of water. This relationship is illustrated in Fig. 7. Compared to neat water, there is more than one and a half fold increase in the latent heat of vaporization at a water mole fraction of 0.2 . 


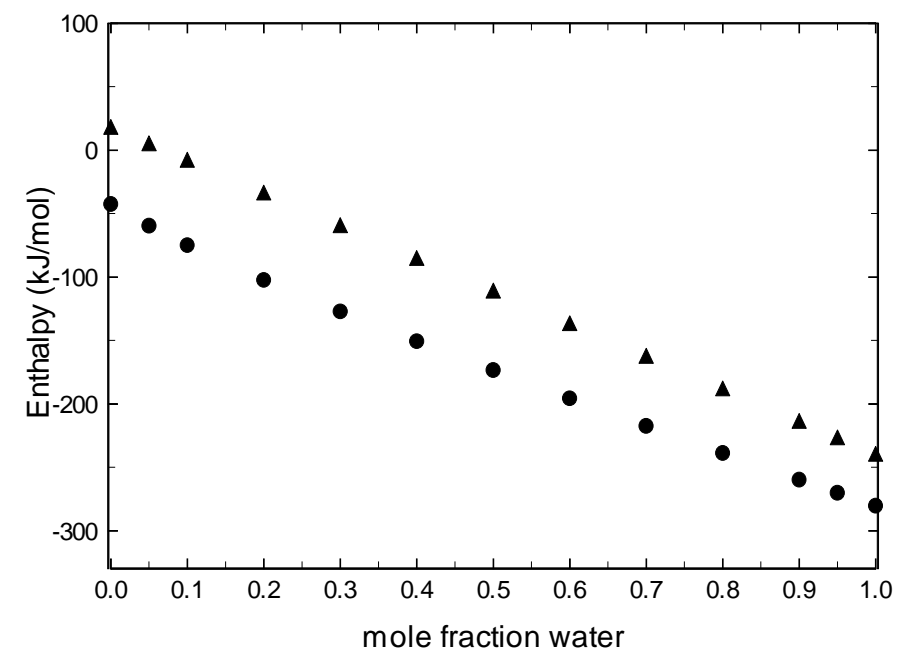

Fig. 6. Enthalpies of the saturated vapor at the dew point, and saturated liquid at the bubble point.

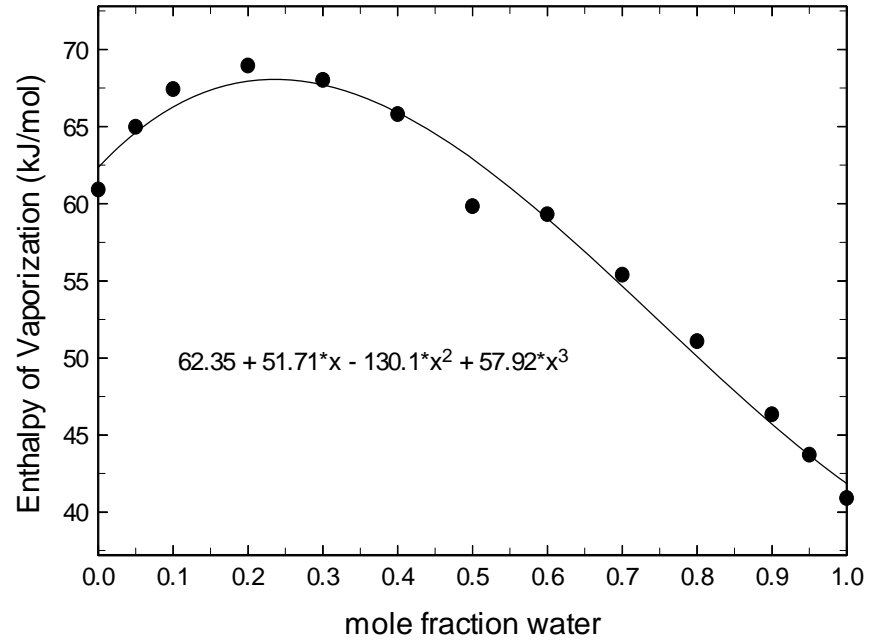

Fig. 7. Enthalpy of vaporization of lactic acid/water mixtures at $p=0.101 \mathrm{MPa}$ as a function of the mole fraction of water.

Figure 8 shows the suppression results for $5.4 \%$ (mole fraction), $13.7 \%$, and $22.4 \%$ lactic acid in water. The undiluted lactic acid stock solution was not tested because it was so viscous that it caused the syringe pump used to deliver the liquid to the nebulizer to stall. The blow-off velocity decreases with increasing liquid application rate. As more of the mixture is delivered to the flame, less airflow is required to induce extinction. Equivalently, the opposed-flow diffusion flame is blown off at lower strain rates. The slopes of the lines in Fig. 8 are a measure for the effectiveness of a liquid in suppressing a flame. The steeper the slope the more effective is the liquid. It can be seen that the three lactic acid/water mixtures show no improvement of fire suppression effectiveness over neat water. In fact, the fire suppression effectiveness decreases as the lactic acid concentration increases. Given that no chemical effects are to be expected for fire suppression with lactic acid, it can be concluded that the increased heat extraction due to lactic acid is being overwhelmed by heat release due to the combustion of this acid.

Since there are many liquid delivery rates that one can use in the screening procedure, a reference delivery rate is needed to compare and interpret the fire suppression effectiveness of various liquid agents in a consistent way. The reference liquid delivery rate is obtained by linearly extrapolating the experimental results to a reference blow-off velocity of $30 \mathrm{~cm} / \mathrm{s}$, which is based on the conditions commensurate with cup-burner extinguishment results for nitrogen, argon, and helium. The rationale for selecting this 
reference blow-off velocity is given in Yang et al. [14]. Table 2 compares the results at the reference velocity for water and the three lactic acid/water mixtures in both mass and mole fractions. The amount of lactic acid/water mixture required to cause extinction for the reference condition actually increases with increasing mole fraction of lactic acid. For this reason, the synergism of lactic acid/water mixtures was not examined further.

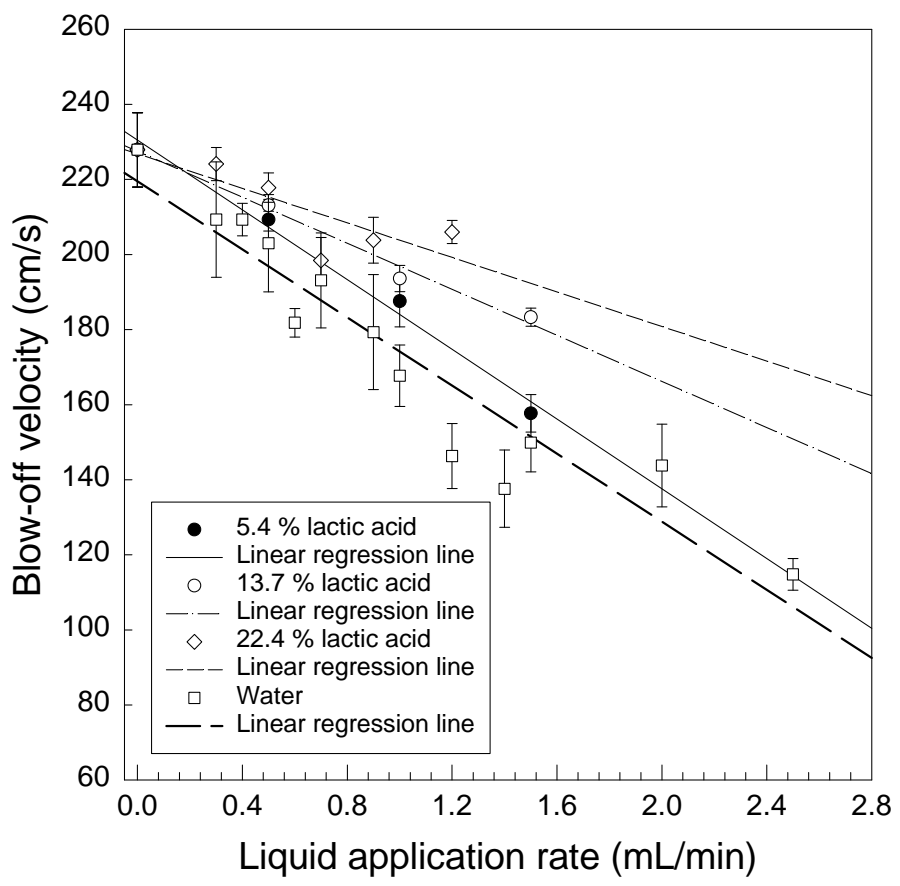

Fig. 8. Blow-off velocity as a function of liquid application rate for lactic acid/water mixtures at three mole fractions of lactic acid. Each data point in the figure represents an average of 5 or more runs. The error bars represent one standard deviation.

The relative effectiveness of HFE7100 was tested in the DLAFSS using the same experimental procedures described above for the lactic acid/water mixtures. Extrapolating to the reference blow-off velocity yields the effective molar and mass fraction extinguishing concentrations of $1.5 \%$ and $11.7 \%$, respectively. These values have been included in Table 2 .

Table 2. Calculated equivalent mass and mole fractions for the reference blow-off velocity.

\begin{tabular}{|l|c|c|}
\hline \multicolumn{1}{|c|}{ Agent } & Equivalent mass percent (\%) & Equivalent mole percent (\%) \\
\hline Water & 2.3 & 3.7 \\
\hline $22.1 \%$ lactic acid & 2.5 & $2.1^{*}$ \\
\hline $44.3 \%$ lactic acid & 3.8 & $3.9^{*}$ \\
\hline $59 \%$ lactic acid & 5.1 & $6.7^{*}$ \\
\hline HFE7100 & 11.7 & 1.5 \\
\hline
\end{tabular}

*Mole-fraction averaged molecular weight of lactic acid /water mixture is used in the calculation.

HFE 7100 was also evaluated in the modified TARPF facility. For these tests, the airflow in the tunnel was fixed at $6.67 \times 10^{-3} \mathrm{~m}^{3} / \mathrm{s}$. The porous burner was operated with a propane flow rate of $33 \mathrm{~mL} / \mathrm{s}$. The mist nozzle had a flow rate of $1.9 \mathrm{~mL} / \mathrm{s}$ at $1.03 \mathrm{MPa}$. The mist discharge duration was varied from $1 \mathrm{~s}$ to $10 \mathrm{~s}$. The hot surface used to investigate re-ignition was not activated. The only heating of this surface came 
from the impinging flame. Based on these test conditions and assuming that the mist droplets are homogeneously dispersed in the carrier phase (air), the mass fraction of agent was calculated to be 0.30 .

For these operating conditions, it was found that the pool fire stabilized behind the backward-facing step could not be completely suppressed by the HFE7100 mist. Observations concerning the suppression process can be summarized as follows. Before the mist application, the flame was luminous and yellow. During the mist application, the yellow flame was nearly extinguished with pockets of persistent, blue flames anchored along the flame attachment points at the outer edges of the bluff body. The duration of the small blue flames coincided with the mist application. Once the mist application was over, the flames resumed their original burning intensity and yellow luminosity.

It was somewhat surprising to find that it was not possible to extinguish the propane flames for these test conditions. The nominal effective mass fraction of the HFE7100 for the current experiments is more than twice as high as that required for extinguishing a propane flame in the DLAFSS (11.7\%). A similar behavior was observed when water was tested [17].

The difference in the two experimental apparatus (DLAFSS vs. TARPF) is almost certainly associated with agent distribution and entrainment in the TARPF. The mass fraction of HFE7100 cited is a nominal value, and it is unclear how evenly distributed the agent was in the wind tunnel. There may be regions in the cross section near the flame front that have actual HFE7100 concentrations below those required for flame extinguishment. It is also possible that efficient extinguishment requires entrainment of the agent into the recirculating zone located behind the bluff body used for flame attachment in the TARPF. It is likely that droplets of agent dispersed in the high-speed airflow have sufficient momentum to pass above the recirculating zone without ever being entrained. In this way, it would be possible to have an extinguishing concentration of liquid agent in the air above the flame, but a lower concentration in the actual location where the flame is stabilized. In either case, the results demonstrate the importance of agent distribution for effective flame extinguishment.

The results of a detailed chemical-kinetic modeling study [1] suggested that the effectiveness of a gaseous thermal agent does not depend on the location of heat extraction relative to the flame front as long as the heat extraction is complete and the gases are convected into the flame zone. If the same holds true for liquid agents, it should be possible to estimate the required effective liquid concentration assuming full vaporization of the agent and using a thermal analysis similar to that suggested by Eq. 1. Based on Figs. 1 and 2, the largest fraction of heat absorption by HFE7100 takes place due to gas-phase heating, with liquidphase processes contributing roughly $10 \%$ of the overall heat extraction. The detailed chemical-kinetic modeling study of the extinction behavior of a propane counterflow flame by gaseous HFE7100 yielded an estimated extinguishing mole fraction of $7.1 \%$ [1], which is consistent with required cup burner values [12], [19]. Reducing this by $10 \%$ to account for the heat absorbed by the liquid yields an estimate of $6.4 \%$ for the effective mole fraction of liquid agent required to extinguish a propane flame. This value is more than four times larger than observed experimentally in the DLAFSS, i.e. flame extinguishment by the liquid is four times more effective than expected based on thermodynamic argument alone. This point will be discussed further in the following based on the results of using water droplets as a thermal agent in the DLAFSS.

Despite the wide spread use of fire-fighting agents released as liquids, note that liquid water remains the most frequently used means for fire fighting and that halon 1301 is generally released as a pressurized liquid. There are very few studies that have considered the direct interaction of a flame with liquid droplets such as reported here. This is particularly surprising given the importance of water for practical fire fighting.

In an early study, Seshadri [20] investigated the extinguishment of heptane, methanol, and wood flames in counterflow configurations using water droplets. The droplets were small enough that they were considered to have evaporated before reaching the flame surfaces. Ewing et al. [21] cite unpublished values for water that lie in the range of $5.5 \%$ to $13.3 \%$ for the effective mole fraction of water (assuming complete evaporation) for diffusion flames.

Zegers et al. [22] have reported extinction results for a propane opposed-jet diffusion flame using various sized water droplets. The effectiveness of the water for inhibiting the flame varied with nominal droplet diameter. Similar to the current investigation, the study was performed using strain rates that were 
considerably higher than are characteristic of buoyancy-dominated flames. In order to estimate extinguishing concentrations it is necessary to extrapolate the findings to appropriate lower strain rates. Simple extrapolation of the results to strain rates characteristic of buoyancy-dominated flames provides estimates of $1.3 \%, 4.6 \%$, and $5.2 \%$ mass fractions $(2.1 \%, 6.4 \%$, and $8.1 \%$ mole fractions $)$ for droplets having nominal diameters of $14 \mu \mathrm{m}, 30 \mu \mathrm{m}$, and $42 \mu \mathrm{m}$, respectively. Lazzarini et al. [23] have reported similar extinction measurements for a methane/air opposed-jet flame using droplets with a median diameter of $20 \mu \mathrm{m}$. Extrapolation of their results leads to estimated extinguishing concentrations of $3.3 \%$ (mass fraction) and $5.2 \%$ (mole fraction). The nominal water mass fraction obtained from the DLAFSS is $2.3 \%$ with nominal droplet size range between $25 \mu \mathrm{m}$ and $35 \mu \mathrm{m}$. Even though these estimates must be considered qualitative and do not consider fuel effects, the agreement among the three investigations is encouraging.

From Figs. 1 and 2, it can be estimated that roughly one half of the heat extracted by heating water from room temperature to flame temperatures arises from heating of the liquid and vaporization. Based simply on thermal considerations, one would therefore predict an extinguishing mole fraction of nearly $17 \%$ for propane flames. Again, these simple arguments result in a substantial overestimate of the amount of required agent as compared to the extrapolated experimental values.

Experimental extinguishment measurements using liquid agents are difficult and are subject to substantial uncertainties. Furthermore, it is necessary to extrapolate from relatively high strain rates to the lower strain rates characteristic of buoyancy-dominated flames. However, based on the existing data, it appears that liquid agents expected to act simply as thermal agents are considerably more effective than would be predicted based simply on their ability to extract heat from a flame zone. Other physical processes may be playing a role. If such effects are actually present, it may be possible to tailor liquid properties to improve the effectiveness of liquid agents. Additional studies of the effectiveness of fire extinguishing agents released as liquids should be performed with a focus on confirming and understanding their enhanced performance relative to that expected based on simple heat extraction.

\section{ACKNOWLEDGEMENTS}

This work is supported by the U.S. Department of Defense's (DoD) Next Generation Fire Suppression Technology Program (NGP), funded by the DoD Strategic Environmental Research and Development Program (SERDP). Dr. Richard G. Gann of NIST was the technical program manager. The authors would also like to thank Mr. Michael Selepak of NIST for his assistance in the TARPF experiments.

\section{REFERENCES}

[1] Pitts, W.M., Yang, J.C., Bryant, R.A, Huber, M.L., and Blevins, L.G., "Characterization and Identification of Super-Effective Thermal Fire Extinguishing Agents: Final Report," Technical Note TN 1440, National Institute of Standards and Technology, Gaithersburg, MD, 2006.

[2] "DIPPR Data Compilation of Pure Compound Properties Database, V9.02," NIST Standard Reference Data Program \#11, National Institute of Standards and Technology, Gaithersburg MD, 1995. Newer version is now available, see http://dippr.byu.edu/

[3] "NIST Thermodynamic Properties of Refrigerants and Refrigerant Mixtures Database (REFPROP), version 5.0," NIST Standard Reference Data Program \#23, National Institute of Standards and Technology, Gaithersburg MD, 1996, and version 6.0, 1998. Newer version is now available, see http://www.nist.gov/srd/nist23.htm

[4] Heathfield, A.E., Anastasi, C., Pagsberg, P., and McCulloch, A., (1998) Atmospheric Lifetimes of Selected Fluorinated Ether Compounds, Atmospheric Environment 32: 711-717, http://dx.doi.org/10.1016/S1352-2310(97)00330-0

[5] Grzyll, L.R., Back, D.D., Ramos, C., and Samad, N.A., "Development of a Rapid Screening Technique for Second-Generation Halon Alternatives," SBIR Phase II Final Report, Contract Number DAAH01-93-C-R150, 1996.

[6] Minor, B., Compositions Including a Three Carbon Cyclic Fluoroether, U.S. Patent No. 5480572, 1996. 
[7] Minor, B., Compositions Including a Fluoroamine and a Second Component, U.S. Patent No. $5441659,1995$.

[8] Minor, B., Chisolm, T.E.C., and Shealy, G.S., Azeotrope (Like) Compositions with Fluoromethyl Trifluoromethyl Ether and Dimethyl Ether, U.S. Patent No. 5607616, 1997.

[9] Pitts, W.M., Nyden, M.R., Gann, R.G., Mallard, W.G., and Tsang, W., "Construction of an Exploratory List of Chemicals to Initiate the Search for Halon Alternatives," Technical Note TN 1279, National Institute of Standards and Technology, Gaithersburg, MD, 1990.

[10] Sekiya, A. and Misaki, S., (1996) A Continuing Search for New Refrigerant, Chemtech 26 (12): 44-48.

[11] 3M Corporation; web site http://www.mmm.com/fluids/7100.html.

[12] Flynn, R.M. and Thomas, S.D., Fire Extinguishing Process and Composition, U. S. Patent No. 5718293, February 17, 1998.

[13] Hamins, A., Gmurczyk, G., Grosshandler, W.L., Rehwoldt, R.G., Vazquez, I., Cleary, T., Presser, C., and Seshadri, K., "Flame Suppression Effectiveness," Evaluation of Alternative in-Flight Fire Suppressants for Full-Scale Testing in Simulated Aircraft Engine Nacelles and Dry Bays, Grosshandler W.L., Gann R.G., and Pitts W.M. (eds.), NIST Special Publication SP 861, National Institute of Standards and Technology, Gaithersburg, MD, April, 1994, pp. 345-465.

[14] Yang, J.C., Donnelly, M.K., Privé, N.C., and Grosshandler, W.L., (2001) An Apparatus for Screening Fire Suppression Efficiency of Dispersed Liquid Agents, Fire Safety Journal 36: 55-72, http://dx.doi.org/10.1016/S0379-7112(00)00042-4

[15] Tsuji, H. and Yamaoka, I., (1969) The Structure of Counterflow Diffusion Flames in the Forward Stagnation Region of a Porous Cylinder, Proceedings of the Combustion Institute 12: 997-1005.

[16] Grosshandler, W.L., Hamins, A., McGrattan, K.B., Charagundla, S.R., and Presser, C., (2000) Suppression of a Non-Premixed Flame behind a Step, Proceedings of the Combustion Institute 28: 2957-2964.

[17] Grosshandler, WL, Hamins, A, McGrattan, KB, Presser, C. Transient application, recirculating pool fire agent effectiveness screen: Final report. NGP Project 3A/2/890. NISTIR 6733, National Institute of Standards and Technology, Gaithersburg, MD, April, 2001.

[18] Abderafi, S. and Bounahmidi, T., (1999) Measurement and Estimation of Vapor-Liquid Equilibrium for Industrial Sugar Juice Using the Peng-Robinson Equation of State, Fluid Phase Equilibria 162: 225-240, http://dx.doi.org/10.1016/S0378-3812(99)00184-3

[19] Tapscott, R.E. Personal Communication. New Mexico Engineering Research Institute MERI InHouse Testing, Albuquerque, New Mexico, June 2, 1997.

[20] Seshadri, K., (1978) Structure and Extinction of Laminar Diffusion Flames above Condensed Fuels with Water and Nitrogen, Combust and Flame 33: 197-215, http://dx.doi.org/10.1016/00102180(78)90060-3

[21] Ewing, C.T., Beyler, C.L., and Carhart, H.W., (1994) Extinguishment of Class B Flames by Thermal Mechanisms; Principles Underlying a Comprehensive Theory; Prediction of Flame Extinguishing Effectiveness, Journal of Fire Protection Engineering 6: 23-54, http://dx.doi.org/10.1177/104239159400600103

[22] Zegers, E.J.P., Williams, B.A., Sheinson, R.S., and Fleming, J.W., (2000) Dynamics and Suppression Effectiveness of Monodisperse Water Droplets in Non-Premixed Counterflow Flames, Proceedings of the Combustion Institute 28: 2931-2937.

[23] Lazzarini, A.K., Krauss, R.H., Chelliah, H.K., and Linteris, G.T., (2000) Extinction Conditions of Non-Premixed Flames with Fine Droplets of Water and Water/NaOH Solutions, Proceedings of the Combustion Institute 28: 2939-2945. 
